\title{
Effect of Substrate Type on the Fractal Characteristics of AFM Images of Sputtered Aluminium Thin Films
}

\author{
Fredrick Madaraka MWEMA ${ }^{1 *}$, Esther Titilayo AKINLABI ${ }^{1,3}$, Oluseyi Philip OLADIJO ${ }^{1,2}$ \\ ${ }^{1}$ Department of Mechanical Engineering Science, University of Johannesburg, Auckland Park Kingsway Campus, P.O. BOX \\ 524 Auckland Park, Johannesburg 2006, South Africa \\ ${ }^{2}$ Department of Chemical, Materials and Metallurgical Engineering, Botswana International University of Science and \\ Technology, Private Bag 16, Palapye, Botswana \\ ${ }^{3}$ Department of Mechanical Engineering, Covenant University, P.M.B 1023, Ota, Ogun State, Nigeria \\ crossref http://dx.doi.org/10.5755/j01.ms.26.1.22769
}

Received 12 February 2019; accepted 05 April 2019

\begin{abstract}
The roughness features of aluminum thin films deposited by radio-frequency magnetron sputtering on Ti6Al4V, stainless steel, mild steel and commercially pure titanium substrates are studied via atomic force microscopy. The average roughness, interface width, skewness, kurtosis, roughness exponent, equivalent roughness, lateral correlation length, fractal dimension and Minkowski functionals have been computed for each sample. It is shown that both topology and fractal characteristics of the $\mathrm{Al}$ thin films are greatly influenced by the type of metallic substrate on which it is sputtered. The fractal studies reveal that the fractal dimensions range between 2 and 3, indicating that all the surfaces are self-affine. The Minkowski functionals show that the valleys and plateaus for all the surfaces are highly disconnected since very small positive values of Euler-Poincaré are computed. The differences in roughness characteristics are superficial indication that substrate types affect the nucleation and growth of surface features such as grain sizes and particles during sputtering. Keywords: aluminium thin film, atomic force microscope (AFM), fractal analysis, roughness, topology.
\end{abstract}

\section{INTRODUCTION}

Surface roughness significantly affects the properties of substrates and thin films. For instance, Takadoum and Bennani reported that titanium nitride (TiN) thin films deposited on rough steel substrates have poor adhesion [1]. In other cases, surface roughness has been shown to increase adhesion and cohesion between plasma-sprayed coatings and substrates [2,3]. For microelectronic applications, surfaces of Indium tin oxide (ITO) films should be atomically smooth to avoid electrical leakages; in fact, for such applications the interface width should be $\sim 1 \mathrm{~nm}$ [4], [5]. Talu et al. [6] reported that sputtered ITO films with higher root mean square roughness revealed higher sheet resistance and optical transmittance.

Surface roughness has also been shown to influence other properties such as tribology [7], wettability, transparency and hydrophobicity $[8,9]$ and so many other physical and chemical characteristics of thin films as presented in literature $[10,11]$. As such, detailed characterisation of surface roughness is critical for quality control and optimisation of functionality of the thin films. Mostly, root mean square, average roughness, skewness and kurtosis are used as measures of roughness. Although they are statistically reliable, these measures do not provide information regarding the spatial distribution, patterning and scale-dependency (fractals) of surface morphology $[11,12]$. For detailed characterisation of surface roughness, fractal analysis is used $[13,15]$.

The surface roughness of thin films is influenced by various factors including the substrate type and deposition parameters [10]. The type of substrate has been reported to affect the nucleation, growth and distribution of morphology of thin films [16, 17]. Although various studies such as $[16,17]$ have investigated the effect of substrate type on properties of thin films, little has been reported on the roughness characteristics (topology and fractal) of $\mathrm{Al}$ thin films on different substrates. Therefore, the purpose of this work is to undertake roughness characterisation, based on a fractal analysis, of Al thin films deposited on Ti6Al4V, stainless steel (SS), mild steel (MS) and commercially pure titanium (CpTi) substrates. Aluminium thin films are used as intermetallic layer coating on titanium and its alloys whereas steels and other metals are used as metal barriers for $\mathrm{Al} / \mathrm{Si}$ semiconductors.

\section{EXPERIMENT AND METHODS}

The Al thin films analysed here have been prepared by radio-frequency (RF) magnetron sputtering at $150 \mathrm{~W}$ for 2 hours from a high-purity Al target (99.999 wt.\%) supplied by HHV Limited, UK. At these sputtering parameters, high quality films of thickness of about $500 \mathrm{~nm}$ have been obtained on all the substrates. At very high powers, surfaces with many defects have been obtained from this facility. The sputtered samples have then been sectioned into $10 \times 10 \mathrm{~mm}^{2}$ for atomic force microscopy (AFM) imaging.

The details of sputtering and AFM used in the present work were presented in an earlier work [18]. Prior to sputtering, the four substrate types have been ground with $\mathrm{SiC}$ papers of \#320, \#500, \#800, \#1200 and then finely polished by diamond pastes up to $1 \mu \mathrm{m}$ and mirror

\footnotetext{
* Corresponding author. Tel.: +27-641058575/+254-723015709.

E-mail address: fredrick.mwema@dkut.ac.ke (F.M. Mwema)
} 
appearance and cleaned in ultrasonic bath in ethanol for 3 minutes. The surface roughness of the substrates was then determined using AFM at scan size of $30 \times 30 \mu \mathrm{m}^{2}$ and optical surface profiler methods. The polishing was repeatedly undertaken to achieve consistent roughness values of all the substrates and reduce the effect of the substrate roughness on the fractal characteristics of the deposited Al films. The values obtained ranged between $2-4 \mu \mathrm{m}$ across the surfaces of the substrates. Additionally, all the substrates were pre-sputtered within the vacuum chamber before deposition to improve on the uniformity of the substrate roughness.

For each surface, five AFM images of sizes $256 \times 256$ pixels and scan areas of $3 \times 3 \mu^{2}$ have been obtained and taken through Nanoscope V530r3sr3 software for computation of interface width, average roughness, skewness and coefficient of kurtosis according to the methods described in earlier publications [18, 19]. The average roughness ( $\mathrm{Ra})$ is determined as $\mathrm{Ra}=\frac{1}{\mathrm{~L}_{\mathrm{x}} \mathrm{L}_{\mathrm{y}}} \sum_{\mathrm{j}=1}^{\mathrm{L}_{\mathrm{y}}} \sum_{\mathrm{i}=1}^{\mathrm{L}_{\mathrm{x}}}\left|\mathrm{h}_{\mathrm{ij}}-\mu\right|$ whereas that of the interface width $(\mathrm{Rq})$ as; $\mathrm{Rq}=\sqrt{\frac{1}{\mathrm{~L}_{\mathrm{x}} \mathrm{L}_{\mathrm{y}}} \sum_{\mathrm{j}=1}^{\mathrm{L}_{\mathrm{y}}} \sum_{\mathrm{i}=1}^{\mathrm{L}_{\mathrm{x}}}\left(\mathrm{h}_{\mathrm{ij}}-\mu\right)^{2}}$ where mean ( $\mu$ ) is determined as $\mu=\frac{1}{\mathrm{~L}_{\mathrm{x}} \mathrm{L}_{\mathrm{y}}} \sum_{\mathrm{j}=1}^{\mathrm{L}_{\mathrm{y}}} \sum_{\mathrm{i}=1}^{\mathrm{L}_{\mathrm{x}}} \mathrm{h}_{\mathrm{ij}}$. The parameters $L_{x}, L_{y}$ represent the sampling length and $h_{i j}$ is the profile height function of the surface. The surface skewness $\left(R_{s k}\right)$ is determined as $\mathrm{R}_{\mathrm{sk}}=\frac{1}{\mathrm{~L}_{\mathrm{x}} \mathrm{L}_{\mathrm{y}} \mathrm{Rq}^{3}} \sum_{\mathrm{j}=1}^{\mathrm{L}_{\mathrm{y}}} \sum_{\mathrm{i}=1}^{\mathrm{L}_{\mathrm{x}}}\left(h_{\mathrm{ij}}-\mu\right)^{3}$ while the coefficient of kurtosis $\left(\mathrm{R}_{\mathrm{ku}}\right)$ as $\mathrm{R}_{\mathrm{ku}}=\frac{1}{\mathrm{~L}_{\mathrm{x}} \mathrm{L}_{\mathrm{y}} \mathrm{Rq}^{4}} \sum_{\mathrm{j}=1}^{\mathrm{L}_{\mathrm{y}}} \sum_{\mathrm{i}=1}^{\mathrm{L}_{\mathrm{x}}}\left(\mathrm{h}_{\mathrm{ij}}-\mu\right)^{4}-3$.

Fractal analyses have been undertaken by height-toheight $(\mathrm{H}(\mathrm{r}))$, power spectral density (PSDF) functions and two-dimensional Minkowski measurements. The H(r)
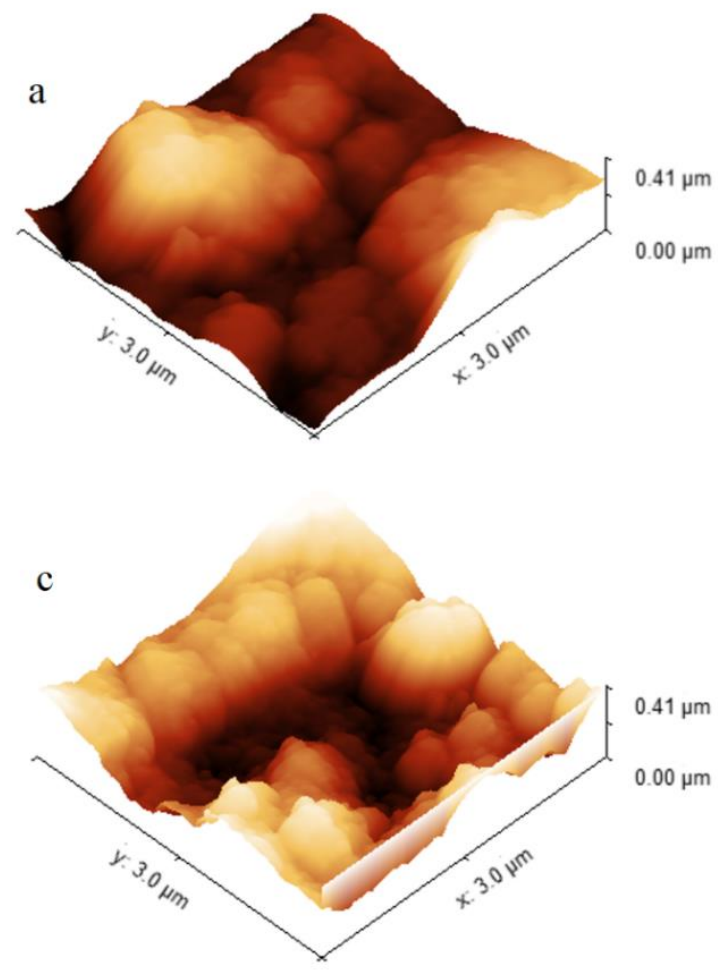

computation was based on the equations presented by Yadav et al. [13], [14] whereas the PSDFs have been determined using the method presented by $[11,18]$ in $M A T L A B{ }^{\circledR}$. The $\mathrm{H}(\mathrm{r})$ formula for an image area of $\mathrm{m} \times \mathrm{m}$ can be written as $\mathrm{H}(\mathrm{r}=\mathrm{ld})=\frac{1}{\mathrm{~m}(\mathrm{~m}-\mathrm{l})} \sum_{\mathrm{j}=1}^{\mathrm{m}} \sum_{\mathrm{i}=1}^{\mathrm{m}-1}[\mathrm{~h}(\mathrm{i}+\mathrm{l}, \mathrm{j})-$ $h(i, j)]^{2}$ where $d$ is the lateral distance between any two adjacent pixels and 1 is the immediate pixel before point $\mathrm{m}$ under consideration. Finally, the Minkowski functionals (MFs), have been computed according to Gwyddion 2.28 software [20, 21]. These MFs are computed according to the number of pixels above the threshold (white), $\mathrm{N}_{\text {white }}$, black (pixels above the threshold, $\mathrm{N}_{\text {black }}$ ) and intermediate pixels (black-white boundary pixels), $\mathrm{N}_{\text {bound }}$.

Statistical analyses have been performed using $M A T L A B ® R 2017$ and 30-day trial MINITAB 17 (available in Www.minitab.com) in which analysis of variance (ANOVA) and then Tukey tests have been undertaken to evaluate the differences among the average of values obtained for each sample at different regions. For all the surfaces, $P>0.05$, which means that the differences among the averages were statistically insignificant.

\section{RESULTS AND DISCUSSION}

\subsection{Topographic observations}

Fig. 1 shows representative AFM micrographs of $\mathrm{Al}$ thin films sputtered on various substrates (a-Ti6Al4V; $\mathrm{b}$-stainless steel; $\mathrm{c}$-mild steel, and $\mathrm{d}$-commercially pure titanium). As shown, the Al films deposited on Ti6Al4V and mild steel substrates have larger surface features, whereas films on stainless steel and pure titanium have smaller features with a higher population of grains.
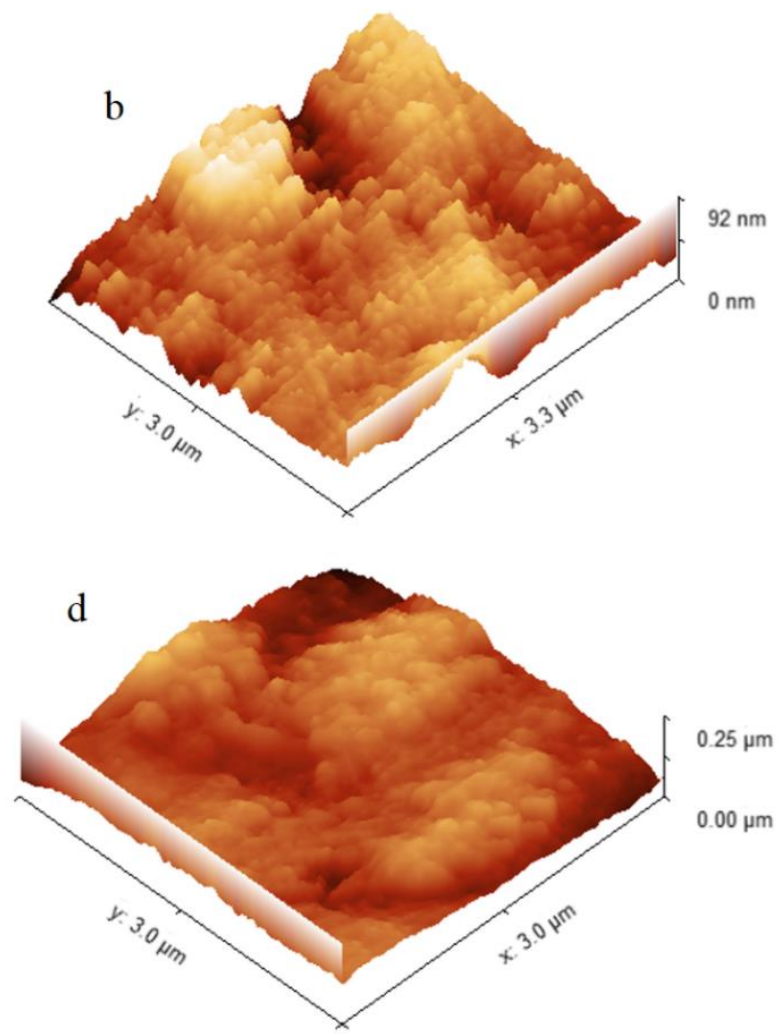

Fig. 1. Representative atomic force micrographs $\left(3 \times 3 \mu \mathrm{m}^{2}\right)$ of surfaces of Al thin films sputtered on: $a-T i 6 A l 4 V ; b-s t a i n l e s s$ steel; $\mathrm{c}$-mild steel; $\mathrm{d}$-commercially pure titanium substrates at power of $150 \mathrm{~W}$ for 2 hours 
Furthermore, the surfaces of films on Ti6Al4V and mild steel have large and continuous trenches indicating presence of surface defects such as cracks and porosity. Lack of the continuous deeps in Fig $1 \mathrm{~b}$ and $\mathrm{d}$ indicates that films sputtered on stainless steel and pure titanium substrates are smooth and porosity-free [22]. The non-cumulative height (or density $(\rho(z))$ distributions corresponding to the various AFM micrographs in Fig. 1 are shown in Fig. 2 alongside with the Gaussian fitting. Fig. 2 shows the plot of peak count $(\rho)$ against the height of the peaks $(Z)$. Peak count is defined as the number of peaks per unit length whereas the peak height is the vertical distance of the maximum points of surface features from the mean height. The generation of data in Fig. 2 is based on ISO 4287-1997. Comparing the results in Fig. 2, it is observed that the average height distribution for all the substrates is $\sim 100 \mu \mathrm{m}$ with a maximum of $250 \mu \mathrm{m}$. The presence of peaks in all the specimens indicates that the surfaces of the films are quite rough, and the surface features are well-oriented onto the substrate. The distribution of particles in films sputtered on stainless steel and pure titanium exhibit a Gaussian distribution while those on Ti6Al4V and mild steel substrates exhibit broad and asymmetrical height distributions. These observations indicate higher roughness in surfaces in Fig. $1 \mathrm{a}$ and $\mathrm{c}$.

The roughness properties of the $\mathrm{Al}$ films are summarized in Table 1 . The results in Table 1 were obtained by averaging measurements from five AFM micrographs obtained at different regions of each sample at same resolutions. The uncertainty of the average values of roughness are also shown in Table 1. The general observation is that these values are small and insignificant to the measurements and such they do not need to be reported. However, these values are included as an indication of closeness of the roughness properties of different regions of the Al thin film. As closely observed, the uncertainty values of values for SS substrates are very small and therefore insignificant, which implies relatively homogenous distribution of the vertical features of $\mathrm{Al}$ thin films on SS substrate. The roughness values of $\mathrm{Al}$ films on Ti6Al4V and mild steel substrates are very high, and this can be attributed to presence of continuous blotches observed in Fig. 1 a.
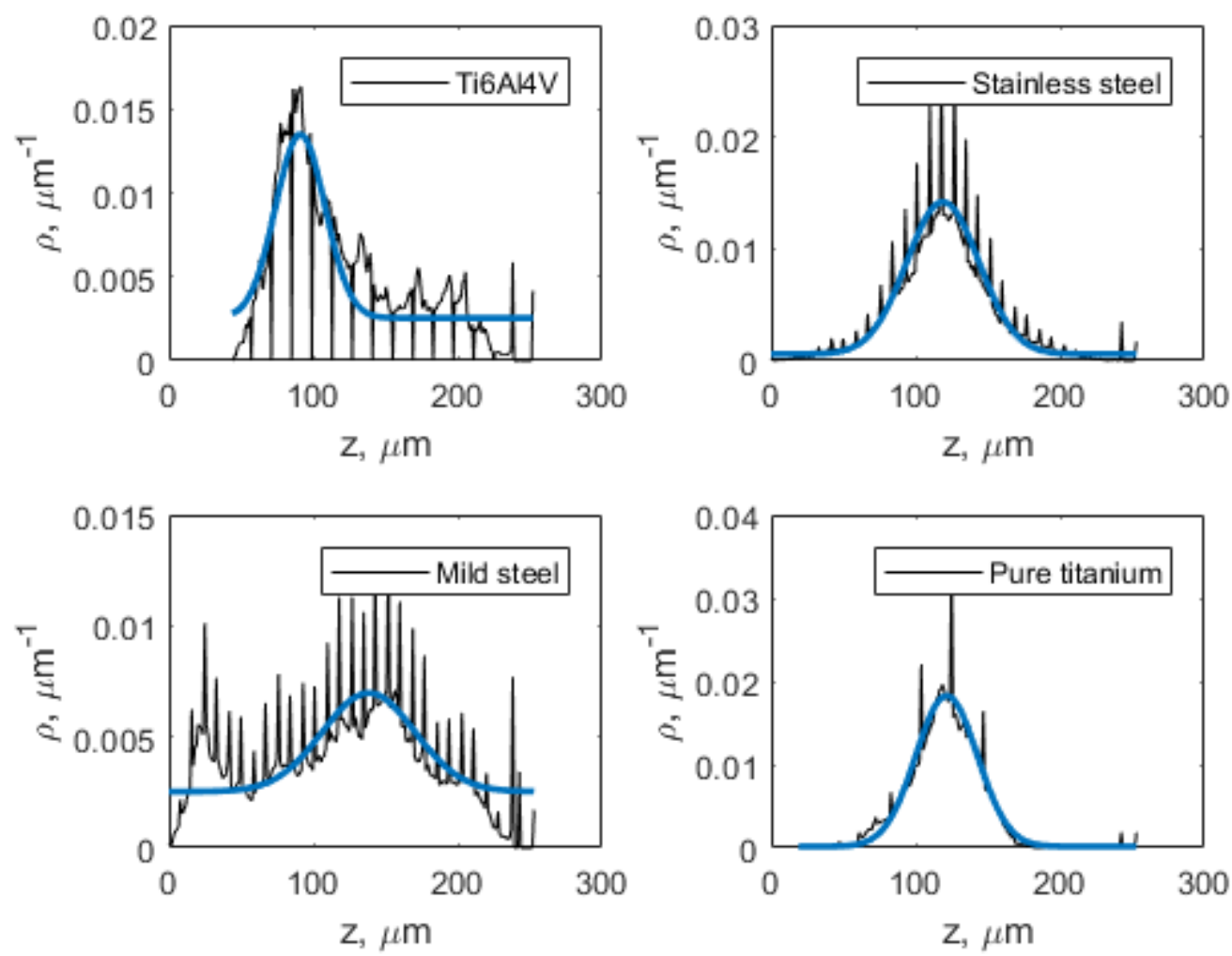

Fig. 2. Height distribution showing peak count per unit length $(\rho)$ against the peak height $(Z)$ for sputtered Al thin films on various substrates. The continuous blue line represents the Gaussian function fit of the data

Table 1. Roughness parameters for Al thin films sputtered on different substrates

\begin{tabular}{|l|c|c|c|c|}
\hline & Ti6Al4V & Stainless steel & Mild steel & Pure titanium \\
\hline Average value, $\mathrm{nm}$ & $149.945 \pm 0.0128$ & $43.5626 \pm 0.0091$ & $202.652 \pm 0.0005$ & $108.681 \pm 0.0013$ \\
\hline RMS roughness $R \mathrm{q}, \mathrm{nm}$ & $88.2046 \pm 0.0108$ & $12.1846 \pm 0.0058$ & $99.7525 \pm 0.0854$ & $25.1316 \pm 0.0173$ \\
\hline Mean roughness $R \mathrm{a}, \mathrm{nm}$ & $73.0016 \pm 0.0099$ & $9.1276 \pm 0.0082$ & $83.3511 \pm 0.0384$ & $19.3726 \pm 0.0101$ \\
\hline Skew $R_{\text {sk }}$ & $0.797829 \pm 0.0158$ & $0.201569 \pm 0.0101$ & $-0.1276 \pm 0.0261$ & $-0.0417 \pm 0.0048$ \\
\hline Kurtosis $R_{\mathrm{ku}}$ & $-0.30255 \pm 0.0131$ & $1.14879 \pm 0.0016$ & $-0.8847 \pm 0.0751$ & $1.96809 \pm 0.0015$ \\
\hline Maximum peak height, nm & $262.063 \pm 0.0201$ & $48.4374 \pm 0.0063$ & $209.348 \pm 0.0105$ & $144.319 \pm 0.0025$ \\
\hline Maximum pit depth, nm & $149.937 \pm 0.0095$ & $43.5626 \pm 0.0192$ & $202.652 \pm 0.0285$ & $108.681 \pm 0.0094$ \\
\hline
\end{tabular}


The largest maximum peak height is observed on films on Ti6Al4V substrates while the smallest is computed for stainless steel substrate. The maximum pit depth measures the difference between the highest peaks and lowest point of the film and very large value may mean presence of exposed surfaces of the substrate [18]. Positive low values of skewness observed indicate slight domination of peaks on the surface whereas negative indicate that the surfaces are dominated by valleys $[23,19]$. When the coefficient of kurtosis is less than three it indicates that the surfaces have less peaks and more valleys. Furthermore, as observed in Fig. $2 \mathrm{~b}$ and d, only films sputtered on stainless steel and pure titanium substrates are tending to Gaussian distribution; their values of kurtosis are nonnegative. To characterise the local morphology of the films, a section analysis diagonally across each sample is reported in Table 2. The topology of all the films exhibits oscillatory behaviour and films deposited on stainless steel and pure titanium have the lowest average wavelengths $(\sim 113$ and $\sim 130 \mathrm{~nm}$ respectively). Lower values of this parameter are an indication of close-packed and well-defined boundaries of the surface features [23]. The average maximum height (Table 2) is highest for films sputtered on mild steel substrates and lowest for those on stainless steel. This parameter can be related to the growth mechanism of the features during the sputtering process and it can be seen in this case that the growth of $\mathrm{Al}$ films varies for different substrates [24]. When the atoms of the target overlay on each other during diffusion on the substrate, a localised higher average maximum height is recorded.

\subsection{Fractal analyses}

Fractal analysis is a method of quantifying the sizes (or lengths) of irregular and self-similar surfaces such as the topography characteristics of thin films. The aim of the procedure is to determine the fractal dimension $(D f)$ of the surfaces. The fractal analyses in this study were conducted using height-height correlation $H(r)$ and power spectral density $(P S D)$ functions. Fig. 3 shows the bi-logarithmic plots of $H(r)$ against $r$ for the four surfaces obtained by implementing the expression described in the methodology. $H(r)$ is a technique for determining the fractal dimension by using the difference in power between points on various surface structures (roughness). The plots are characterised by two regimes; linear region at small values of $r$ and nonlinear region at large values of $r$; the nonlinear regions exhibit oscillatory characteristics. Similar observations have been reported in literature for other thin films [13-15] and are characteristics of self-affine surfaces. Except for samples of Ti6Al4V substrates, the transition point of all the other samples are very distinct. To derive the fractal parameters, power law and Gaussian function are fitted into the data in the linear and nonlinear regions of the $H(r)$ plot respectively.

Table 2. Morphological characteristics from section analysis of the AFM micrographs for the Al thin films on different substrates

\begin{tabular}{|c|c|c|c|c|}
\hline Specimen description & Ti6Al4V & Stainless steel & Mild steel & Pure titanium \\
\hline \multicolumn{5}{|l|}{ Amplitude } \\
\hline Roughness average $R \mathrm{a}, \mathrm{nm}$ & 3.36595 & 1.27817 & 4.49839 & 2.87167 \\
\hline Root mean square roughness $R \mathrm{q}, \mathrm{nm}$ & 4.23197 & 1.71552 & 5.58325 & 3.73977 \\
\hline Maximum height of the roughness $R \mathrm{t}, \mathrm{nm}$ & 27.8060 & 10.9984 & 29.5252 & 24.1419 \\
\hline Maximum roughness valley depth $R \mathrm{v}, \mathrm{nm}$ & 12.6568 & 4.65275 & 16.0031 & 11.9893 \\
\hline Maximum roughness peak height $R \mathrm{p}, \mathrm{nm}$ & 15.1492 & 6.34570 & 13.5222 & 12.1526 \\
\hline Average maximum height of the roughness $R \mathrm{tm}, \mathrm{nm}$ & 18.3632 & 9.37271 & 24.3523 & 16.8987 \\
\hline Average maximum roughness valley depth $R \mathrm{vm}, \mathrm{nm}$ & 9.36737 & 3.93395 & 12.8140 & 8.68493 \\
\hline Average maximum roughness peak height $R \mathrm{pm}, \mathrm{nm}$ & 8.99587 & 5.43876 & 11.5383 & 8.21375 \\
\hline Average third highest peak to third lowest valley height $R 3 \mathrm{z}, \mathrm{nm}$ & 19.3569 & 8.77728 & 24.9065 & 17.4515 \\
\hline Average maximum height of the profile $R \mathrm{z}, \mathrm{nm}$ & 23.0549 & 9.22494 & 25.4396 & 18.7738 \\
\hline Average maximum height of the roughness $R \mathrm{z}$ ISO, $\mathrm{nm}$ & 18.3632 & 9.37271 & 24.3523 & 16.8987 \\
\hline Maximum peak to valley roughness, $R \mathrm{y}=R \max , \mathrm{nm}$ & 27.8060 & 10.9420 & 29.0687 & 24.1419 \\
\hline Skewness $R$ sk & $22.3776 \times 10^{-3}$ & 0.227833 & -0.03752 & -0.08990 \\
\hline Kurtosis $R \mathrm{ku}$ & 3.43619 & 3.05429 & 2.70899 & 3.06435 \\
\hline Waviness average $W \mathrm{a}, \mathrm{nm}$ & 70.8538 & 6.85847 & 87.5618 & 23.0841 \\
\hline Root mean square waviness $\mathrm{Wq}, \mathrm{nm}$ & 81.7632 & 8.47358 & 106.092 & 28.5766 \\
\hline Waviness maximum height $W \mathrm{y}=W \max , \mathrm{nm}$ & 288.352 & 45.2798 & 367.975 & 130.426 \\
\hline Maximum height of the profile $P t, \mathrm{~nm})$ & 299.891 & 47.4671 & 375.011 & 136.388 \\
\hline \multicolumn{5}{|l|}{ Spatial } \\
\hline Mean spacing of profile irregularities $S m, \mathrm{~nm}$ & 148.928 & 98.3789 & 167.291 & 147.184 \\
\hline Average wavelength of the profile $\lambda \mathrm{a}, \mathrm{nm}$ & 141.888 & 113.903 & 150.867 & 133.936 \\
\hline Root mean square (RMS) wavelength of the profile $\lambda \mathrm{q}, \mathrm{nm}$ & 139.443 & 116.768 & 142.745 & 135.332 \\
\hline \multicolumn{5}{|l|}{ Hybrid } \\
\hline Average absolute slope $\Delta \mathrm{a}$ & 0.149053 & 0.0705067 & 0.187345 & 0.134716 \\
\hline Root mean square (RMS) slope $\Delta \mathrm{q}$ & 0.190689 & 0.0923105 & 0.245758 & 0.173630 \\
\hline Length $L, \mu \mathrm{m}$ & 4.02106 & 4.03354 & 4.18228 & 4.12116 \\
\hline Developed profile length, $L_{0}, \mu \mathrm{m}$ & 4.09217 & 4.05057 & 4.30241 & 4.18171 \\
\hline Profile length ratio $l \mathrm{r}$ & 1.01768 & 1.00422 & 1.02872 & 1.01469 \\
\hline
\end{tabular}



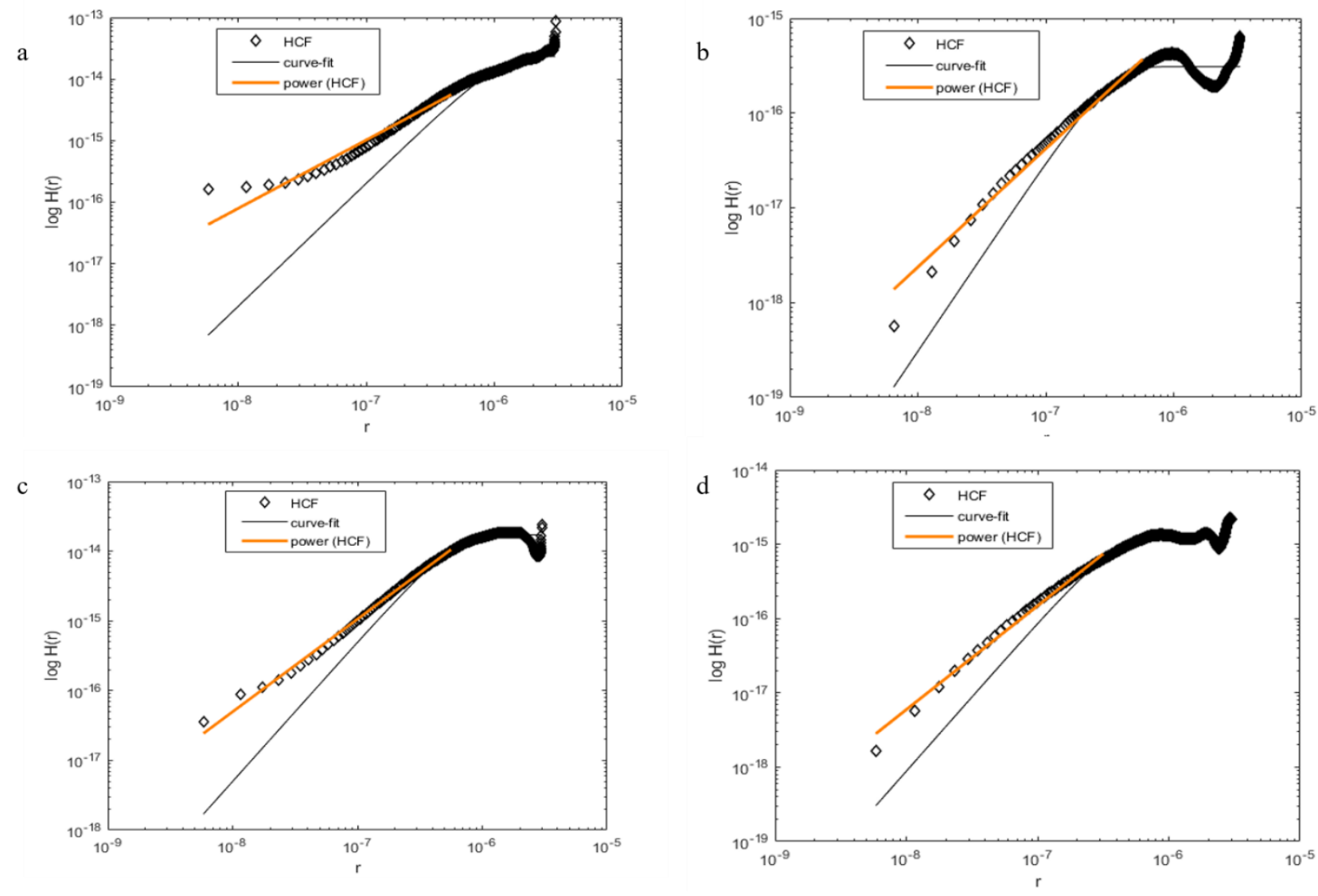

Fig. 3. Bi-logarithmic plots of height-height correlation $(H)$ as a function of shift $(r)$ for Al thin films sputtered on: a-Ti6Al4V; $\mathrm{b}$ - stainless steel; $\mathrm{c}$-mild steel; $\mathrm{d}$-pure titanium. The black and orange lines denote $H(r)$-Gaussian and power law curves respectively of best fit of the $H(r)$ data

Table 3. Fractal parameters of the surfaces analysed through the curve-fitting functions of the height-to-height data

\begin{tabular}{|l|l|c|c|c|c|}
\hline Samples & $R^{2}$ (Power law) & Lateral correlation length & Equivalent roughness & Roughness exponent & Fractal dimension \\
\hline Ti6Al4V & $0.97181 \pm 0.00014$ & $1.0792 \pm 0.0112 \mu \mathrm{m}$ & $107.95 \pm 0.002 \mathrm{~nm}$ & $0.882 \pm 0.003$ & $2.118 \pm 0.04$ \\
\hline Stainless steel & $0.98322 \pm 0.00017$ & $318.18 \pm 0.002 \mathrm{~nm}$ & $12.42 \pm 0.002 \mathrm{~nm}$ & $0.751 \pm 0.005$ & $2.249 \pm 0.03$ \\
\hline Mild steel & $0.99603 \pm 0.00025$ & $412.52 \pm 0.003 \mathrm{~nm}$ & $96.97 \pm 0.001 \mathrm{~nm}$ & $0.670 \pm 0.001$ & $2.33 \pm 0.02$ \\
\hline Pure titanium & $0.99013 \pm 0.00013$ & $378.077 \pm 0.002 \mathrm{~nm}$ & $25.08 \pm 0.003 \mathrm{~nm}$ & $0.599 \pm 0.006$ & $2.401 \pm 0.08$ \\
\hline
\end{tabular}

The fractal properties obtained from this curve fitting are roughness exponent $(\alpha)$, lateral correlation length $(\tau)$, equivalent roughness $\left(R \mathrm{q}_{\mathrm{eq}}\right)$ and fractal dimension $(D \mathrm{f})$ presented in Table 3. The $R^{2}$ values of the power law curvefitting indicate a good estimate of the fractal properties within the linear region. The lateral correlations for films on Ti6Al4V and mild steel substrates are very high compared to the others, which indicate the presence of highly correlated features. These features could be attributed to continuous trenches and surface defects described in Fig. 1. The equivalent root means square roughness obtained through height-height correlation functions are consistent with those reported through the statistical approach. We further observe that the smallest $\alpha$ is obtained on pure titanium surfaces, which implies higher lateral roughness of the surface features [14]. The highest $D$ f is obtained on $\mathrm{Al}$ films deposited on pure titanium and lowest for films on Ti6Al4V substrates. These observations indicate dependence on fractal behaviour on the type of substrate and therefore it means that substrates affect the growth of films in a sputtering process [24].
A further fractal analysis is undertaken through power spectral density functions (PSDF) and the results presented as its double log plots against the spatial frequency in Fig. 4. The plots are characterised by nearly constant PSDF at very low spatial frequency (smooth region), constant slope region and a plateau at very high spatial frequency. These are characteristics of surfaces with dominant random properties (self-affine) and lesser periodic behaviour [25]. To determine the fractal properties of the films through PSDF, we fitted the PSD data within the linear region into inverse power law and obtained the slope $(\gamma)$.

The fractal dimension, $D f$, was determined as $D f=(8-\gamma) / 2[11]$ and the results presented in Table 4 . The $R^{2}$ values show that the inverse power law provided a good fit of the linear region of the PSDF for all the samples. The lateral correlation lengths, roughness exponents and fractal dimensions obtained by PSDF method are comparable to those obtained through height-height correlation function (Table 3). The values of Df obtained through PSDF are slightly higher than those computed through $H(r)$ as can been in Table 3 and Table 4. These observations are 
consistent with literature, where usually $D$ f values obtained through PSDF method are higher than those determined from other methods [26]. Surfaces with large values of $D f$ are said to have higher lateral roughness [27] and in this case films sputtered on pure titanium have the highest fractal dimension. For 2-dimensional fractals, $D$ f is about $\sim 2$ and $\sim 3$ for smooth and rough surfaces respectively and therefore it implies that all the surfaces analysed in this work exhibit fractal characteristics since their $D$ f values lie between 2 and 3 [27].

The 2-dimensional Minkowski functionals, volume $(V)$, boundary length $(S)$ and connectivity/Euler characteristic $(X)$ are plotted in Fig. 5. These measures are used to describe the morphological features which cannot be determined through the classical techniques of image analysis. The summary of Minkowski functionals are presented in Table 5. Minkowski functionals are based on separating the AFM images into two parts (high and low) based on thresholding [28]. The high and low regions represent plateaus and valleys respectively.
Table 5. Minkowski measures computed from Fig. 5

\begin{tabular}{|l|c|c|c|}
\hline Samples & $V$ & $S$ & $X$ \\
\hline Ti6Al4V & 0.3617 & 0.0138 & 0.001395 \\
\hline Stainless steel & 0.5022 & 0.0102 & 0.008217 \\
\hline Mild steel & 0.4897 & 0.0076 & 0.001625 \\
\hline Pure titanium & 0.4273 & 0.00992 & 0.001907 \\
\hline
\end{tabular}

The functional $V$, which basically shows the surface coverage varies across all the samples. As seen in Fig. 5 a, the Minkowski volume is asymmetrical for Ti6Al4V and mild steel substrates about $V=0.5$ whereas for stainless steel (SS) and pure titanium the functionals are symmetrical.

Large values of $V$ indicate dominance of high regions (plateaus) whereas small values indicate that trenches and pinholes (valleys) dominate the surfaces. The films deposited on Ti6Al4V substrates are dominated by trenches and ditches as observed in Fig. 1.

The Minkowski boundary length $(S)$ measures the global perimeter of either region (low or high domain) and has dimensions of length.

Table 4. Fractal parameters of the surfaces analysed through the power spectral density function (PSDF)

\begin{tabular}{|l|c|c|c|c|}
\hline Samples & $R^{2}$ (Power law) & Lateral correlation length & Roughness exponent & Fractal dimension \\
\hline Ti6Al4V & 0.99469 & $914.67 \mathrm{~nm}$ & 0.8275 & 2.1725 \\
\hline Stainless steel & 0.9375 & $334.88 \mathrm{~nm}$ & 0.8235 & 2.1765 \\
\hline Mild steel & 0.99603 & $696.15 \mathrm{~nm}$ & 0.7878 & 2.2122 \\
\hline Pure titanium & 0.99013 & $520.93 \mathrm{~nm}$ & 0.5663 & 2.4337 \\
\hline
\end{tabular}
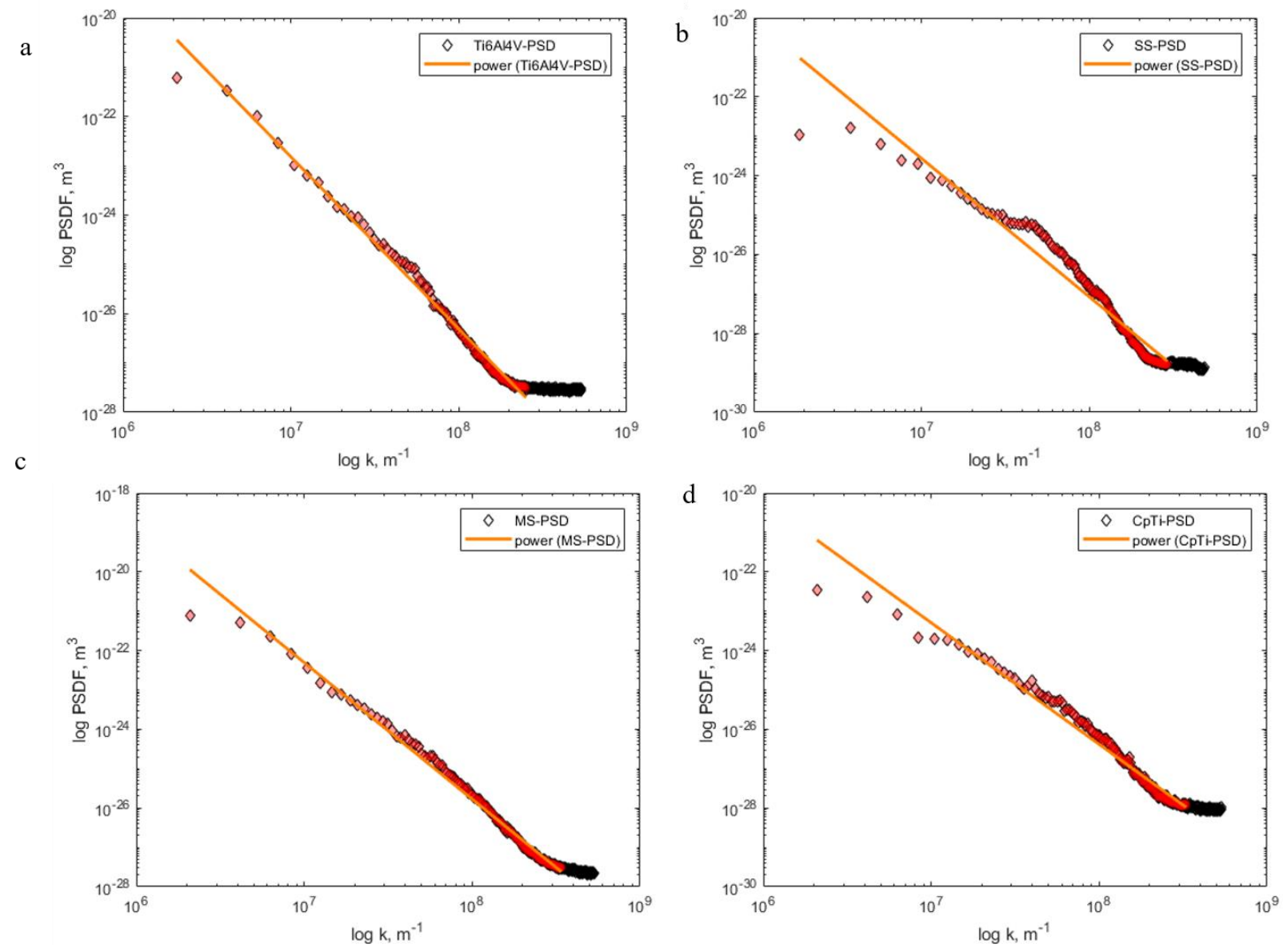

Fig. 4. Double log plots of power spectral density (PSDF) as a function of the spatial frequency for Al thin films sputtered on: a-Ti6Al4V; $\mathrm{b}$-stainless steel; $\mathrm{c}$-mild steel; $\mathrm{d}$-pure titanium substrates. The orange solid line shows the inverse power law best curve of fit 
a
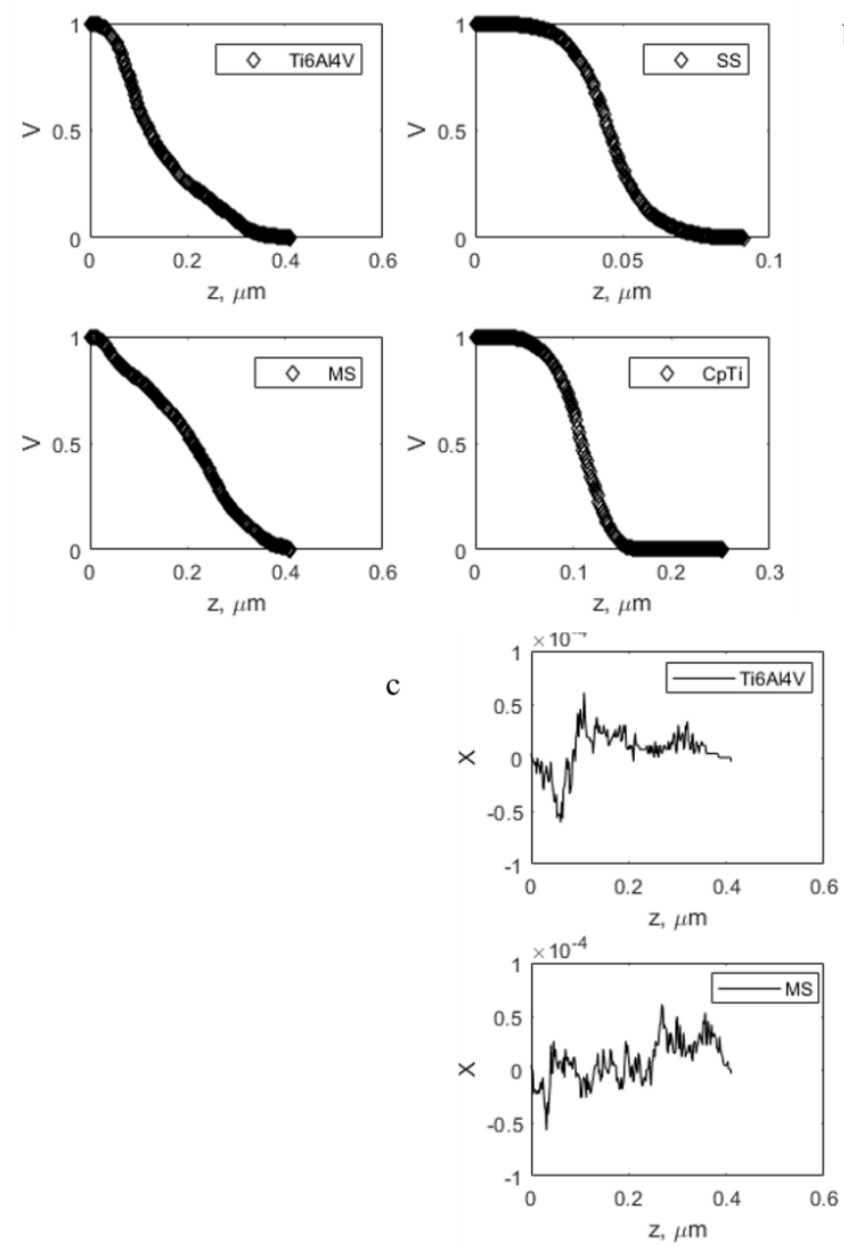

$\mathrm{b}$
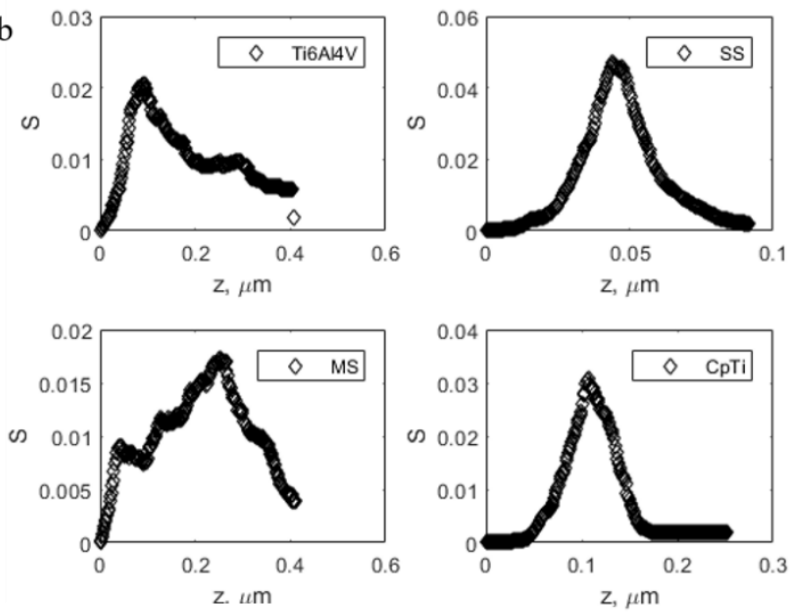

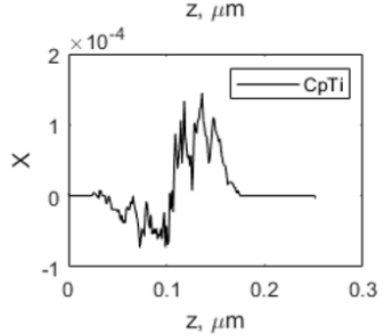

Fig. 5. Two-dimensional Minkowski functionals of Al thin films: a-Minkowski volume, $V$; b-boundary length, $S$; c-Minkowski connectivity, $X$ for Ti6Al4V, stainless steel (SS), mild steel and commercially pure titanium (CpTi)

It describes the nature of surface morphology of films. In Table 5, the boundary lengths of $\mathrm{Al}$ films on Ti6Al4V, stainless steel and pure titanium substrates are $\sim 0.01$, indicating that their morphologies are similar. However, the values of films on stainless steel and pure titanium are closer (with a difference of 0.00028), which indicates that their surface features are similar.

The Minkowski connectivity $(X)$ measures the difference in number of high and low-level regions and it describes the topological pattern (fractal nature) of the AFM micrograph. Positive values of $X$ indicate that the surfaces are dominated by the features of the high domain. In this case, all the connectivity values are positive indicating dominance of plateaus on all the surfaces [28, 29]. However, as shown in Fig. 5 c, these values are too small meaning that there are significant trenches and valleys in all the surfaces especially for films on mild steel and Ti6Al4V. These observations show that valleys and plateaus in $\mathrm{Al}$ thin films deposited on the four substrates are highly disconnected and therefore the lower number of separated domains.

\section{CONCLUSIONS}

The topology and fractal characteristics of Al thin films sputtered on Ti6AlV, stainless steel, mild steel and pure titanium substrates have been characterised through AFM measurements. Topology observations revealed that $\mathrm{Al}$ films sputtered on stainless steel and pure titanium exhibit well-defined and fine surface features whereas those deposited on Ti6Al4V and mild steel have high density of continuous pores and trenches. The highest interface width and average roughness are observed on the surfaces with trenches and defects according to statistical and section analysis. Further analysis revealed that fractal properties of Al thin films vary with substrate type. The fractal dimensions determined through height-height correlation and power spectral density functions lie between 2 and 3 denoting self-affine characteristics of all the thin films. Using the two-dimensional Minkowski functionals, the connectivity and dominance of valleys and plateaus of the Al thin films on different substrates have been described. The results of topology and fractal analyses are well correlated.

\section{Acknowledgments}

We acknowledge the University Research Committee (URC) of the University of Johannesburg for sponsoring this research. 


\section{REFERENCES}

1. Takadoum, J., Bennani, H.N. Influence of Substrate Roughness and Coating Thickness on Adhesion, Friction and Wear of Tin Films Surface \& Coatings Technology $96(2-3)$ 1997: pp. 272-282.

https://doi.org/10.1016/S0257-8972(97)00182-5

2. Matěiíček, J., Vilémová, M., Mušálek, R., Sachr, R., Horník, J. The Influence of Interface Characteristics on The Adhesion/Cohesion of Plasma Sprayed Tungsten Coatings Coatings 3 (2) 2013: pp. 108-125. https://doi.org/10.3390/coatings3020108

3. Mellali, M., Fauchais, P., Grimaud, A. Influence of Substrate Roughness and Temperature on The Adhesion/Cohesion of Alumina Coatings Surface \& Coatings Technology 81 (2-3) 1996: pp. 275-286. https://doi.org/10.1016/0257-8972(95)02540-5

4. Raoufi, D. Fractal Analyses of ITO Thin Films: A Study Based on Power Spectral Density Physica B Condensed Matter 405 (1) 2010: pp. $451-455$. https://doi.org/10.1016/j.physb.2009.09.005

5. Sohn, M.H., Kim, D., Kim, S.J., Paik, N.W., Gupta, S. Super-Smooth Indium-Tin Oxide Thin Films by Negative Sputter Ion Beam Technology Journal of Vacuum Science Technology A Vacuum, Surfaces, Film 21 (4) 2003: pp. $1347-1350$.

https://doi.org/10.1116/1.1577127

6. Țălu, S., Kulesza, S., $\quad$ Bramowicz, B., Pringle, A.M., Pearce, J.M., Murugesan, M., Venkatachalapathy, V., Mayandi, J. Micromorphology Analysis of Sputtered Indium Tin Oxide Fabricated with Variable Ambient Combinations Materials Letters 220 2018: pp. 169-171. https://doi.org/10.1016/j.matlet.2018.03.005

7. Vilt, S.G., Caswell, C.J., Tuberquia, J.C., McCabe, C., Jennings, G.K. Effect of Roughness on the Microscale Friction of Hydrocarbon Films Journal of Physical Chemistry C 116 (41) 2012: pp. 21795-21801. https://pubs.acs.org/doi/abs/10.1021/jp305527h

8. Xu, L., Karunakaran, R.G., Guo, J., Yang, S. Transparent, Superhydrophobic Surfaces from One-Step Spin Coating of Hydrophobic Nanoparticles ACS Applied Material Interfaces 4 (2) 2012: pp. 1118-1125. https://doi.org/10.1021/am201750h

9. Cho, K.L., Liaw, I.I., Wu, A.H.F., Lamb, R.N. Influence of Roughness on a Transparent Superhydrophobic Coating Journal of Physical Chemistry C 114 (25) 2010: pp. $11228-11233$. https://pubs.acs.org/doi/abs/10.1021/jp103479k

10. Mwema, F.M., Oladijo, O.P., Akinlabi, S.A., Akinlabi, E.T. Properties of Physically Deposited Thin Aluminium Film Coatings: A Review Journal of Alloys and Compounds 747 2018: pp. 306-323. https://doi.org/10.1016/j.jallcom.2018.03.006

11. Gong, Y., Misture, S.T., Gao, P., Mellott, N.P. Surface Roughness Measurements Using Power Spectrum Density Analysis with Enhanced Spatial Correlation Length Journal of Physical Chemistry C 120 (39) 2016: pp. 22358-22364. https://pubs.acs.org/doi/abs/10.1021/acs.jpcc.6b06635

12. Senthilkumar, M., Sahoo, N.K., Thakur, S., Tokas, R.B. Characterization of Microroughness Parameters in Gadolinium Oxide Thin Films: A Study Based On Extended Power Spectral Density Analyses Applied Surface Science 252 (5) 2005: pp. 1608-1619.

https://doi.org/10.1016/j.apsusc.2005.02.122

13. Yadav, R.P., $\quad$ Dwivedi, S., Mittal, A.K., Kumar, M.,
Pandey, A.C. Fractal and Multifractal Analysis of LiF Thin Film Surface Applied Surface Science 261 (5) 2012: pp. $547-553$. https://doi.org/10.1016/j.apsusc.2012.08.053

14. Yadav, R.P., Kumar, M., Mittal, A.K., Dwivedi, S., Pandey, A.C. On the Scaling Law Analysis of Nanodimensional LiF Thin Film Surfaces Materials Letters 126 2014: pp. $123-125$. https://doi.org/10.1016/j.matlet.2014.04.046

15. Yadav, R.P., Kumar, M., Mittal, A.K., Pandey, A.C. FractalaAnd Multifractal Characteristics of Swift Heavy Ion Induced Self-Affine Nanostructured $\mathrm{BaF}_{2}$ Thin Film Surfaces Chaos: An Interdisciplinary Journal of Nonlinear Science 25 (8) 2015: pp. 83115. https://doi.org/10.1063/1.4928695

16. Wang, F.H., Chang, C.L. Effect of Substrate Temperature on Transparent Conducting Al And F Co-Doped Zno Thin Films Prepared by RF Magnetron Sputtering Applied Surface Science 370 2016: pp. 83-91. https://doi.org/10.1016/j.apsusc.2016.02.161

17. Spinler, S., Schmidbauer, S., Klotzsche, J. Surface Roughness Reduction for $\mathrm{AlCu}$-Based Metallization: Implications from an Integrative Point of View Microelectronic Engineering 50 (1-4) 2000: pp. 311-319. https://doi.org/10.1016/S0167-9317(99)00297-X

18. Mwema, F.M., $\quad$ Oladijo, O.P., $\quad$ Sathiaraj, T.S., Akinlabi, E.T. Atomic Force Microscopy Analysis of Surface Topography of Pure Thin Aluminium Films Material Resource Express 5 (4) 2018: pp. 046416. https://doi.org/10.1088/2053-1591/aabe1b

19. Aqil, M., Azam, M., Aziz, M., Latif, R. Deposition and Characterization of Molybdenum Thin Film Using Direct Current Magnetron and Atomic Force Microscopy Journal of Nanotechnology 2017: pp. 1-10. https://doi.org/10.1155/2017/4862087

20. Nečas, D., Klapetek, P. Gwyddion: An Open-Source Software for SPM Data Analysis Central European Journal of Physics 10 (1) 2012: pp. 181-188. https://doi.org/10.2478/s11534-011-0096-2

21. Țălu, S., $\quad$ Stach, S., $\quad$ Ghodselahi, T., $\quad$ Ghaderi, A., Solaymani, S., Boochani, A., Garczyk, Z. Topographic Characterization of Cu-Ni Nps @ A-C:H Films by AFM and Multifractal Analysis Journal of Phyical Chemistry B 119 (17) 2015: pp. 5662-5670. https://pubs.acs.org/doi/abs/10.1021/acs.jpcb.5b00042

22. Ramzan, M., Ahmed, E., Niaz, N.A., Rana, A.M., Bhatti, A.S., Khalid, N.R., Nadeem, M.Y. AFM Applications to Study the Morphology of $\mathrm{HFO}_{2}$ Multilayer Thin Films Superlattices and Microstructures 82 2016: pp. 399-405. https://doi.org/10.1016/j.spmi.2015.02.030

23. Gadelmawla, E.S., Koura, M.M., Maksoud, T.M.A., Elewa, I.M., Soliman, H.H. Roughness Parameters Journal of Materials Processing Technology $123(1)$ 2002: pp. $133-145$. https://doi.org/10.1016/S0924-0136(02)00060-2

24. Khachatryan, H., Lee, S., Kim, K.B., Kim, H.K., Kim, K. Al Thin Film: The effect of Substrate Type on Al Film Formation and Morphology Journal of Physics and Chemistry of Solids 122 2018: pp. 109-117. https://doi.org/10.1016/j.jpcs.2018.06.018

25. Buchko, C.J., Kozloff, K.M., Martin, D.C. Surface Characterization of Porous, Biocompatible Protein Polymer Thin Films Biomaterials 22 (11) 2001: pp. 1289-1300. https://doi.org/10.1016/S0142-9612(00)00281-7 
26. Douketis, C., Wang, Z., Haslett, T.L., Moskovits, M. Fractal Character of Cold-Deposited Silver Films Determined by Low-Temperature Scanning Tunneling Microscopy Physical Review B 51 (16) 1995: pp. 11022-11031. https://doi.org/10.1103/PhysRevB.51.11022

27. Militký, J., Bajzík, V. Surface Roughness and Fractal Dimension Journal of Textile Institute 92 (3) 2001: pp. $91-113$.

https://doi.org/10.1080/00405000108659617
28. Salerno, M., Banzato, M. Minkowski Measures for Image Analysis in Scanning Probe Microscopy Microscopy and Analysis 19 (4) 2005: pp. 13-15.

29. Mwema, F.M., $\quad$ Akinlabi, E.T., Oladijo, O.P., Majumdar, J.D. Effect of Varying Low Substrate Temperature on Sputtered Aluminium Films Materials Research Express 6 (5) 2019: pp. 056404. https://doi.org/10.1088/2053-1591/ab014a 